Supplement of Geosci. Model Dev., 12, 2285-2306, 2019

https://doi.org/10.5194/gmd-12-2285-2019-supplement

(C) Author(s) 2019. This work is distributed under

the Creative Commons Attribution 4.0 License.

(c) (1)

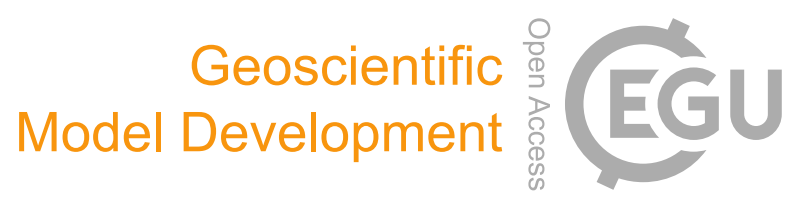

Supplement of

\title{
DECIPHeR v1: Dynamic fluxEs and ConnectIvity for Predictions of HydRology
}

\section{Gemma Coxon et al.}

Correspondence to: Gemma Coxon (gemma.coxon@bristol.ac.uk)

The copyright of individual parts of the supplement might differ from the CC BY 4.0 License. 


\section{Additional Model Evaluation}

In this supplementary document we provide additional analysis of the national-scale model simulations described in 'DECIPHeR v1: Dynamic fluxEs and ConnectIvity for Predictions of HydRology', Coxon et al.

Figure S1 shows the ability of the model to simulate observed flow percentiles (Q95, Q50 and Q5). The results show that for many of the catchments the model can capture these flow percentiles. However, the model tends to overpredict the flow percentiles (particularly for Q5) in drier catchments where runoff is low. These results are consistent with the model results presented in the main paper.
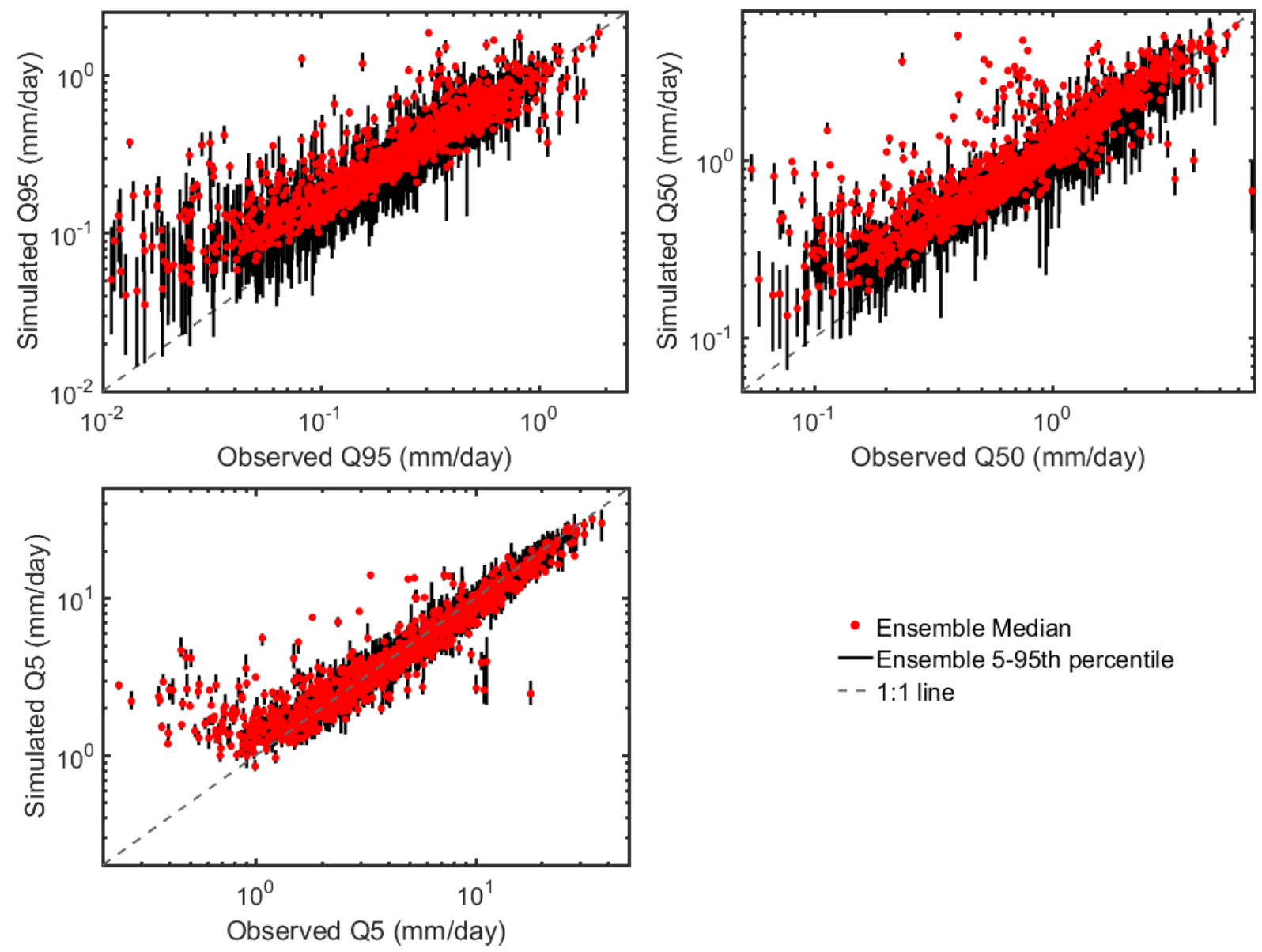

- Ensemble Median

-Ensemble 5-95th percentile

$--1: 1$ line

Figure S1. Observed and simulated flow percentiles for each gauge. The red scatter point signifies the median value of the simulated flow percentiles from the behavioural simulations, while the black line shows the $5^{\text {th }}-95^{\text {th }}$ percentile of the simulated flow percentiles from the behavioural simulations 